\title{
Wall Structure of the Neurospora Hyphal Apex: Immunofluorescent Localization of Wall Surface Antigens
}

\author{
By D. HUNSLEY* \\ Department of Agricultural Science, University of Oxford, Oxford \\ AND D. KAY \\ Sir William Dunn School of Pathology, University of Oxford
}

(Received 2 October 1975 ; revised 22 February 1976)

S UMMARY

\begin{abstract}
Antisera have been raised in rabbits against three wall fractions from Neurospora crassa. Fractions were separated according to Mahadevan \& Tatum (I965), i.e. fraction I, glucan-peptide-galactosamine complex; fraction III, laminarin-like glucan; and fraction IV, chitin. Distinct patterns of immunofluorescent staining were obtained using an indirect staining method. Hyphae stained with antiserum to fraction I showed maximum fluorescence in the apical and/or subapical regions: in both cases, fluorescence showed a sharp decrease with distance behind the subapical region. Hyphae stained with antiserum to fraction III showed faintly fluorescent tips with fluorescence increasing with distance from the tip. Hyphae stained with antiserum to fraction IV showed faint fluorescence, equivalent to leveis of autofluorescence, except at the sites of hyphal fractures. Antisera were also raised against whole walls from 24 and $120 \mathrm{~h}$ cultures. Hyphae stained with antisera against whole walls which had previously been absorbed to remove antibodies to fractions I, III and IV showed preferential staining of apices. The uncharacterized tip antigen(s) thus revealed was also demonstrated on immunodiffusion plates. This pattern of immunofluorescence was compared to the fluorescence of apices after staining with an optical brightener.

Enzymic dissection procedures did not generally give reliable results with apices from $24 \mathrm{~h}$ cultures. Untreated apices appeared amorphous, while a drastic chemical treatment revealed randomly oriented microfibrils which were shown to be $\alpha$-chitin. The apical hyphal walls were significantly thinner than those from more mature hyphal regions.
\end{abstract}

\section{INTRODUCTION}

Previous work (Hunsley \& Burnett, 1970) has suggested that the walls at hyphal apices of young, actively growing $24 \mathrm{~h}$ Neurospora cultures show some differences in structure from mature wall areas from $\mathrm{I} 20 \mathrm{~h}$ cultures. In $\mathrm{I} 20 \mathrm{~h}$ cultures, the reticulate structure of the hyphal wall appeared to be covered with a layer of amorphous laminarin-like glucan. In $24 \mathrm{~h}$ cultures, this reticulum was visible on the hyphal surface but appeared to be absent from apices and developed progressively subapically, becoming covered with amorphous material in older hyphal regions. The object of the present study was to confirm the apparent surface distribution of wall components described above. This has been accomplished by immunofluorescence using antibodies to specific wall fractions.

* Present address: The Medical School, The University, Newcastle upon Tyne NEI 7 RU. 


\section{METHODS}

Organism. Neurospora crassa wild type FGSC352 was obtained from the Fungal Genetics Stock Center, Arcata, California; U.S.A. Cultures were grown in defined medium in liquid shake cultures as described previously (Hunsley \& Burnett, I968, 1970) for either 24 or I $20 \mathrm{~h}$. Material for inoculation was obtained by blending $24 \mathrm{~h}$ cultures, which were themselves grown from blends of $24 \mathrm{~h}$ seed cultures.

Electron microscopy. Material for sectioning was fixed for $30 \mathrm{~min}$ in $2 \%(\mathrm{w} / \mathrm{v})$ phosphatebuffered glutaraldehyde ( $\mathrm{pH} 7 \cdot 4$ ), washed several times in buffer, postfixed in I \% (w/v) phosphate-buffered $\mathrm{OsO}_{4}$ for $2 \mathrm{~h}$, dehydrated in a graded ethanol series, and embedded in Araldite. Sections were stained in $\mathrm{I} \%(\mathrm{w} / \mathrm{v})$ alcoholic uranyl acetate followed by lead citrate (Reynolds, 1963). Material for shadow casting was coated with palladium/gold $(60: 40)$ at an angle of $I 8^{\circ}$. Measurements of wall thickness were made on sectioned material as described previously (Hunsley, 1973). Enzymic dissection methods and drastic chemical treatments were as described by Hunsley \& Burnett (1968, 1970). Infrared spectra of chemically treated material were obtained with a Perkin-Elmer i.r. spectrophotometer using the $\mathrm{KBr}$ disc method ( $\mathrm{I} \cdot 5$ to $2.0 \mathrm{mg}$ chemically treated material in $300 \mathrm{mg} \mathrm{KBr}$ ). Material given the drastic chemical treatment was also examined in a Philips X-ray diffractometer using $\mathrm{Cu} K_{\alpha}$ radiation. The reference standard in both cases was crustacean chitin (Koch-Light), purified as described by Skujins, Potgieter \& Alexander (I 965 ).

Hyphal wall preparation and fractionation. Hyphal walls were prepared from $\mathrm{I} 20 \mathrm{~h}$ and $24 \mathrm{~h}$ cultures by grinding in liquid nitrogen followed by ultrasonication in an MSE $20 \mathrm{kHz}$ I00 W disintegrator using a water-cooled vessel. Treatments were of $\mathrm{I}$ min duration, with 2 min cooling periods in between. Precautions were taken to keep wall preparations cold at all stages of the procedure. The disintegrated walls were stirred overnight in cold $\mathrm{I} \%(\mathrm{w} / \mathrm{v})$ aqueous sodium lauryl sulphate; and then they were repeatedly centrifuged in distilled water at $2000 \mathrm{~g}$ until phase-contrast microscopy indicated removal of cytoplasmic contamination. Walls were then freeze-dried and stored until required.

Wall fractionation procedures were based on those of Mahadevan \& Tatum (1965). The following fractions were isolated:

Fraction I. This fraction was soluble at room temperature $\left(22^{\circ} \mathrm{C}\right)$ in $2 \mathrm{M}$-sodium hydroxide, and could be recovered by ethanol precipitation in the cold. It was identified by Mahadevan \& Tatum (1965) as a glucan-peptide-galactosamine complex; and Hunsley \& Burnett (I970) suggested that, morphologically, this corresponded to the reticulate structure of the Neurospora hyphal wall.

Fraction III. This was a second 2 M-sodium hydroxide soluble fraction of the wall, which was solubilized after treating the walls with I M-sulphuric acid at $90^{\circ} \mathrm{C}$ for $\mathrm{I} 6 \mathrm{~h}$. This fraction was identified by Madadevan \& Tatum (I965) as a $(\mathrm{I} \rightarrow 3)$ - $\beta$-linked glucan similar to laminarin.

Fraction IV. This was the residual material after the wall fractionation above, and was identified as chitin by Mahadevan \& Tatum (I965).

Fraction II, which consisted of simple sugars would be unlikely to be immunogenic, and was discarded in this work.

After dialysis against distilled water, wall fractions were freeze-dried and stored at $-\mathrm{I} 8{ }^{\circ} \mathrm{C}$ until required.

Immunological methods. Antisera were raised in rabbits against wall fractions I, III and IV as well as against whole wall preparations from $24 \mathrm{~h}$ and $\mathrm{I} 20 \mathrm{~h}$ cultures.

Antigen preparations were made at $30 \mathrm{mg} \mathrm{ml}^{-1}$ in phosphate-buffered saline $(\mathrm{pH} 7 \cdot 2$ ). 
Antigens were dispersed in the saline by ultrasonic treatment for short periods in a watercooled vessel. Precautions were taken to ensure that the ultrasonic probe and vessels were sterile and they were cleaned in chromic acid between treatments to prevent cross-contamination of antigens.

Rabbits were injected with a I:I mixture of antigen and Freund's complete adjuvant. The injection schedule was based on that of Holland \& Choo (1970), with a series of Io subcutaneous injections extending over a period of 4 weeks. After I week the animals were bled from a marginal ear vein. Sera were stored at $4{ }^{\circ} \mathrm{C}$. Antisera were fractionated to separate $\gamma$-globulins by double precipitation with saturated ammonium sulphate, as described by Goldman (1968). Precipitated globulins were centrifuged, redissolved in distilled water equal in volume to the original volume of serum, and dialysed against phosphate-buffered saline before use. In some cases globulins were concentrated by dialysis against solid sucrose. Antibody production in rabbits was demonstrated using three techniques:

Complement fixation. The test, which was used here as a qualitative test only, was carried out using all preliminary titrations and controls as described by Oakley (197I).

Agglutination using a capillary tube method (Oakley, 1971). This was used as a method of assaying antibody titres.

Immunodiffusion (Ouchterlony, 1964). Diffusion experiments were performed in Petri dishes containing I \% (w/v) Ion agar (Oxoid no. I) in phosphate-buffered saline $\mathrm{pH} 7 \cdot \mathbf{2}$ containing $1 \mathrm{IO}^{-3} \mathrm{M}$-sodium azide. In each plate the centre well contained antiserum and the peripheral wells, antigen digests. Central and peripheral wells were separated by a distance of $0.5 \mathrm{~cm}$.

Attempts were made to separate antigenic materials from wall fractions and wall preparations by using enzymic digests and ultrasonic treatment in the presence of $0 . \mathrm{I} \%$ sodium lauryl sulphate. The following enzymic digests were used: for fraction I, separate digests of laminarinase (EC. 3.2.1.6) and trypsin (EC. 3.4.21.4); for fraction III, laminarinase; for fraction IV, chitinase (EC. 3.2. I . I4); and for walls from 24 and I $20 \mathrm{~h}$ cultures, separate digests of laminarinase and trypsin. Digestions were performed for $3 \mathrm{~h} \mathrm{at} 37^{\circ} \mathrm{C}$ using $2 \mathrm{mg}$ antigenic material $/ \mathrm{ml}$ and $0.1 \mathrm{mg}$ enzyme in a total volume of $2 \mathrm{ml}$. Ouchterlony plates were used to test for cross-reactivity of sera with non-homologous wall antigens. Antisera showing cross-reactivity were absorbed with their non-specific cross-reacting antigens before use.

Immunodiffusion plates were either stained with naphthalene black (Sargent, 197I) or mounted on an indirect illumination device for photography.

Fluorescent staining of hyphal material. Hyphal material was stained using the antiglobulin method of Weller \& Coons (1954). Mycelia were fixed for $20 \mathrm{~min}$ in acetone at $4{ }^{\circ} \mathrm{C}$ and then allowed to react with the appropriate rabbit antisera for $30 \mathrm{~min}$ at room temperature before being washed several times with phosphate-buffered saline and stained with fluorescein-conjugated sheep anti-rabbit immunoglobulin (Burroughs Wellcome) for $30 \mathrm{~min}$. This globulin was used at a dilution of at least $\mathrm{I}: 6$ to avoid non-specific staining effects. After staining, mycelia were washed several times in phosphate-buffered saline,

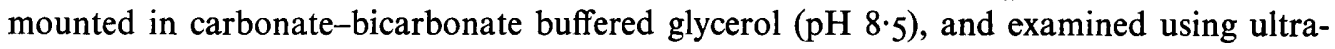
violet illumination in a Reichert Zetopan microscope fitted with filters $\mathrm{E}_{2}$ and $\mathrm{Sp}_{2}$. Fluorescent images were recorded on Ilford $\mathrm{HP}_{4}$ film using exposure times of 2 to $2.5 \mathrm{~min}$. Various control procedures used for the immunofluorescence experiments are detailed in Table 4.

Optical brightener staining of hyphae. In some instances, hyphal material was stained with a $0.05 \%$ aqueous solution of the optical brightener Calcofluor White M2R New (Cyanamid), mounted in $0.1 \mathrm{M}$-phosphate buffer $(\mathrm{pH} 7 \cdot 5)$ and examined in the u.v. microscope. 
Table I. Immunodiffusion reactions of unabsorbed antisera and wall antigen extracts

\begin{tabular}{|c|c|c|c|}
\hline Antiserum against: & $\begin{array}{l}\text { Immunoprecipitation } \\
\text { with antigens of: }\end{array}$ & Extraction method & $\begin{array}{l}\text { No. of } \\
\text { precipitin lines }\end{array}$ \\
\hline Wall fraction I & $\begin{array}{l}\text { Fraction I } \\
\text { Fraction I } \\
\text { Fraction III } \\
\text { Fraction IV }\end{array}$ & $\begin{array}{l}\text { Laminarinase } \\
\text { Trypsin } \\
\text { Laminarinase } \\
\text { Chitinase }\end{array}$ & $\begin{array}{l}3 \\
2 \\
2 \\
2\end{array}$ \\
\hline Wall fraction III & $\begin{array}{l}\text { Fraction I } \\
\text { Fraction I } \\
\text { Fraction III } \\
\text { Fraction IV }\end{array}$ & $\begin{array}{l}\text { Laminarinase } \\
\text { Trypsin } \\
\text { Laminarinase } \\
\text { Chitinase }\end{array}$ & $\begin{array}{l}\mathbf{I} \\
0 \\
\mathbf{I} \\
\mathbf{0}\end{array}$ \\
\hline Wall fraction IV & $\begin{array}{l}\text { Fraction I } \\
\text { Fraction I } \\
\text { Fraction III } \\
\text { Fraction IV }\end{array}$ & $\begin{array}{l}\text { Laminarinase } \\
\text { Trypsin } \\
\text { Laminarinase } \\
\text { Chitinase }\end{array}$ & $\begin{array}{l}0 \\
0 \\
0 \\
2\end{array}$ \\
\hline Walls from $24 \mathrm{~h}$ cultures & $\begin{array}{l}\text { Fraction I } \\
\text { Fraction I } \\
\text { Fraction III } \\
\text { Fraction IV } \\
24 \text { h culture walls } \\
24 \text { h culture walls } \\
\text { I } 20 \text { h culture walls } \\
\text { I } 20 \text { h culture walls }\end{array}$ & $\begin{array}{l}\text { Laminarinase } \\
\text { Trypsin } \\
\text { Laminarinase } \\
\text { Chitinase } \\
\text { Laminarinase } \\
\text { Trypsin } \\
\text { Laminarinase } \\
\text { Trypsin }\end{array}$ & $\begin{array}{l}3 \\
2^{*} \\
3 \\
3 \\
2 \\
1 \\
2^{*} \\
1^{*}\end{array}$ \\
\hline Walls from $\mathrm{I} 20 \mathrm{~h}$ cultures & $\begin{array}{l}\text { Fraction I } \\
\text { Fraction I } \\
\text { Fraction III } \\
\text { Fraction IV } \\
24 \text { h culture walls } \\
24 \text { h culture walls } \\
\text { I } 20 \text { h culture walls } \\
\text { I } 20 \text { h culture walls }\end{array}$ & $\begin{array}{l}\text { Laminarinase } \\
\text { Trypsin } \\
\text { Laminarinase } \\
\text { Chitinase } \\
\text { Laminarinase } \\
\text { Trypsin } \\
\text { Laminarinase } \\
\text { Trypsin }\end{array}$ & $\begin{array}{l}2 \\
0 \\
2 \\
2 \\
4 \\
3 \\
4^{*} \\
4^{*}\end{array}$ \\
\hline
\end{tabular}

* Indicates broad diffuse lines.

Immunoprecipitation

Fraction I

Fraction I

Fraction III

Fraction I

Fraction I

Fraction I

Fraction I

Fraction I

raction I

$24 \mathrm{~h}$ culture walls

$24 \mathrm{~h}$ culture walls

I $20 \mathrm{~h}$ culture walls

All antisera used gave no immunoprecipitating activity in control experiments in which laminarinase, trypsin or chitinase only were used in the antigen wells.

Table 2. Absorption of antisera with cross-reacting antigens

Antiserum against:

Fraction I
Fraction III
Fraction IV
$24 \mathrm{~h}$ culture walls
I $20 \mathrm{~h}$ culture walls

Absorbed with:

Fractions III and IV
Fractions I and IV
Fractions III and I
Fractions I, III and IV
Fractions I, III and IV

Expected residual immunoprecipitating activity against:

\author{
Fraction I \\ Fraction III \\ Fraction IV \\ Possible uncharacterized anti- \\ gens present in $24 \mathrm{~h}$ and $120 \mathrm{~h}$ \\ culture walls?
}

\section{RESULTS}

\section{Antibody production}

Full complement-fixation procedures (Oakley, I97I) demonstrated unequivocally that appropriately inoculated rabbits produced antibodies against the whole walls and wall fractions. Agglutination titres of antisera at the time of bleeding were: antiserum to wall fraction I, I/40; to fraction III, I/80; to fraction IV, I/80; to walls from $24 \mathrm{~h}$ cultures, $\mathrm{I} / \mathrm{I} 60$; to walls from $\mathrm{I} 20 \mathrm{~h}$ cultures, $\mathrm{I} / \mathrm{I} 60$. Because of the low titre of antisera against wall fractions, 
Table 3. Immunodiffusion reactions of absorbed antisera and wall antigen extracts

$\begin{array}{llll}\text { Antiserum against: } & \begin{array}{c}\text { Immunoprecipitation } \\ \text { with antigens of: }\end{array} & \text { Extraction method } & \begin{array}{c}\text { No. of } \\ \text { precipitin lines }\end{array} \\ \text { Fraction I } & \text { Fraction I } & \text { Laminarinase } & \text { I } \\ & \text { Fraction I } & \text { Trypsin } & 0 \\ & \text { Fraction III } & \text { Laminarinase } & 0 \\ \text { Fraction III } & \text { Fraction IV } & \text { Chitinase } & 0 \\ & \text { Fraction I } & \text { Laminarinase } & 0 \\ & \text { Fraction I } & \text { Trypsin } & 0 \\ \text { Fraction IV } & \text { Fraction III } & \text { Laminarinase } & 2 \\ & \text { Fraction IV } & \text { Chitinase } & 0 \\ & \text { Fraction I } & \text { Laminarinase } & 0 \\ \text { Walls from } 24 \text { h cultures } & \text { Fraction I } & \text { Trypsin } & 0 \\ & \text { Fraction III } & \text { Laminarinase } & 0 \\ & \text { Fraction IV } & \text { Chitinase } & \text { I } \\ & \text { Fraction I } & \text { Laminarinase } & 0 \\ & \text { Fraction III } & \text { Laminarinase } & 0 \\ \text { Walls from I 20 h cultures } & \text { Fraction IV } & \text { Chitinase } & 0 \\ & 24 \text { h culture walls } & \text { Trypsin } & 2 \\ & \text { I20 h culture walls } & \text { Trypsin } & 2 \\ & \text { Fraction I } & \text { Laminarinase } & 0\end{array}$

* Indicates broad diffuse line.

All absorbed antisera gave no immunoprecipitating activity in control experiments in which laminarinase, trypsin or chitinase were used in the antigen wells.

the antiglobulin activity was concentrated by ammonium sulphate fractionation and dialysis against solid sucrose.

The results of immunodiffusion experiments are presented in Tables I and 3. Table I shows that all antisera except that prepared against wall fraction IV (chitin) show considerable cross-reactivities with other antigens. Cross-reacting antisera were therefore absorbed with their non-homologous cross-reacting antigens before use. Absorption procedures are given in Table 2. The results of immunodiffusion experiments with absorbed antisera are presented in Table 3. The antisera against wall fractions I and III did not show any crossreactivities with each other after absorption. Fraction IV had not previously shown crossreactivity with other wall fractions, and was absorbed with fractions I and III purely as a precautionary procedure.

Absorption procedures, detailed in Table 2, using antisera to whole walls resulted in the removal of immunoprecipitating activity against extracts of fractions I and III which were formerly cross-reacting with whole-wall antisera (see Table 3). However, in both cases activity was retained against extracts of antigen(s) from walls of 24 and $\mathrm{I} 20 \mathrm{~h}$ cultures. Absorbed antiserum to walls from $\mathrm{I} 20 \mathrm{~h}$ cultures still showed some activity against fraction IV. In both cases, the precipitin lines on the immunodiffusion plates against whole walls showed reactions of partial or total identity indicating the presence of a common uncharacterized antigen or antigens in walls from $24 \mathrm{~h}$ and $120 \mathrm{~h}$ cultures.

Table 3 also shows that absorption procedures used on antisera to fractions I and III resulted in removal of cross-reactivities with other wall fractions. (Antiserum to fraction IV did not previously show any cross-reactivity.)

The results of absorption and immunoprecipitation with antisera to wall fractions I, III 
Table 4. Control procedures for immunofluorescence

Antiserum treatment of mycelium

\begin{tabular}{|c|c|c|}
\hline First & Second & Fluorescence* \\
\hline None & None & A \\
\hline Normal serum & Labelled sheep $\dagger$ & A \\
\hline Normal serum & None & A \\
\hline None & Labelled sheep $\dagger$ & A \\
\hline Antiserum to $24 \mathrm{~h}$ culture walls $\ddagger$ & None & A \\
\hline Antiserum to $24 \mathrm{~h}$ culture walls & Labelled sheep $\dagger$ & Strong green fluorescence \\
\hline Antiserum to $\mathrm{I} 20 \mathrm{~h}$ culture walls $\ddagger$ & None & A \\
\hline Antiserum to $\mathrm{I} 20 \mathrm{~h}$ culture walls & Labelled sheep $\dagger$ & Strong green fluorescence \\
\hline
\end{tabular}

and IV indicated that these absorbed antisera could act as reasonably specific immunological stains for immunofluorescence.

Attempts to demonstrate release of wall antigens from whole wall preparations by ultrasonic and detergent treatments were unsuccessful.

\section{Immunofluorescence}

The untreated hyphae (both unfixed, and those fixed in cold acetone) had a very faint blue-white autofluorescence, as do hyphae stained using a variety of control procedures.

Immunofluorescence micrographs of hyphae from $24 \mathrm{~h}$ cultures of Neurospora crassa.

All bar markers represent $10 \mu \mathrm{m}$.

Fig. I. Hypha treated with absorbed antiserum to wall fraction I, showing a type of fluorescence which is maximal in the subapical region and fades to a low level 30 to $50 \mu \mathrm{m}$ behind the apex.

Fig. 2. Hyphae treated with absorbed antiserum to wall fraction I, showing a type of fluorescence in which apices and subapical regions are equally fluorescent; fluorescence again decreases to a low level about 50 to $100 \mu \mathrm{m}$ behind the apex.

Fig. 3. Hyphae treated with absorbed antiserum to wall fraction III, showing a low level of fluorescence in the apical region, increasing with distance from the apex. Note that the apical dome is particularly well defined as an area of low level fluorescence and also that septa are apparent as regions of non-fluorescence (arrowed).

Figs 4 and 5. Hyphae treated with absorbed antiserum to fraction IV. Appreciable fluorescence is only seen in the region of hyphal breaks. In Fig. 4, the hypha has broken a short distance from a septum: bright fluorescence is seen extending from the break to the septum only, suggesting that the septal pore is plugged. In Fig. 5, the break has occurred at the site of a septum and fluorescence is visible for a short distance from the hyphal side of the septum, suggesting that here the pore is not plugged. Both figures indicate that the antibody to fraction IV is attached predominantly to the inside surface of the hyphal wall.

Fig. 6. Hypha treated with unabsorbed antiserum to $24 \mathrm{~h}$ culture walls. Note the even distribution of fluorescence. If unabsorbed antiserum to $120 \mathrm{~h}$ culture walls is used, the appearance is similar.

Fig. 7. Hypha treated with unabsorbed antiserum to $24 \mathrm{~h}$ culture walls, showing a brightly fluorescent hyphal apex. Only a few hyphae had this appearance.

Fig. 8. Hyphae treated with absorbed antiserum to $\mathrm{I} 20 \mathrm{~h}$ culture walls. Note the brightly fluorescent hyphal apices.

Fig. 9. Fluorescence micrograph showing hypha from a $24 \mathrm{~h}$ culture stained with the optical brightener Calcofluor White M2R New. Note the brightly fluorescent apices. (Bar marker represents Io $\mu \mathrm{m}$.) 

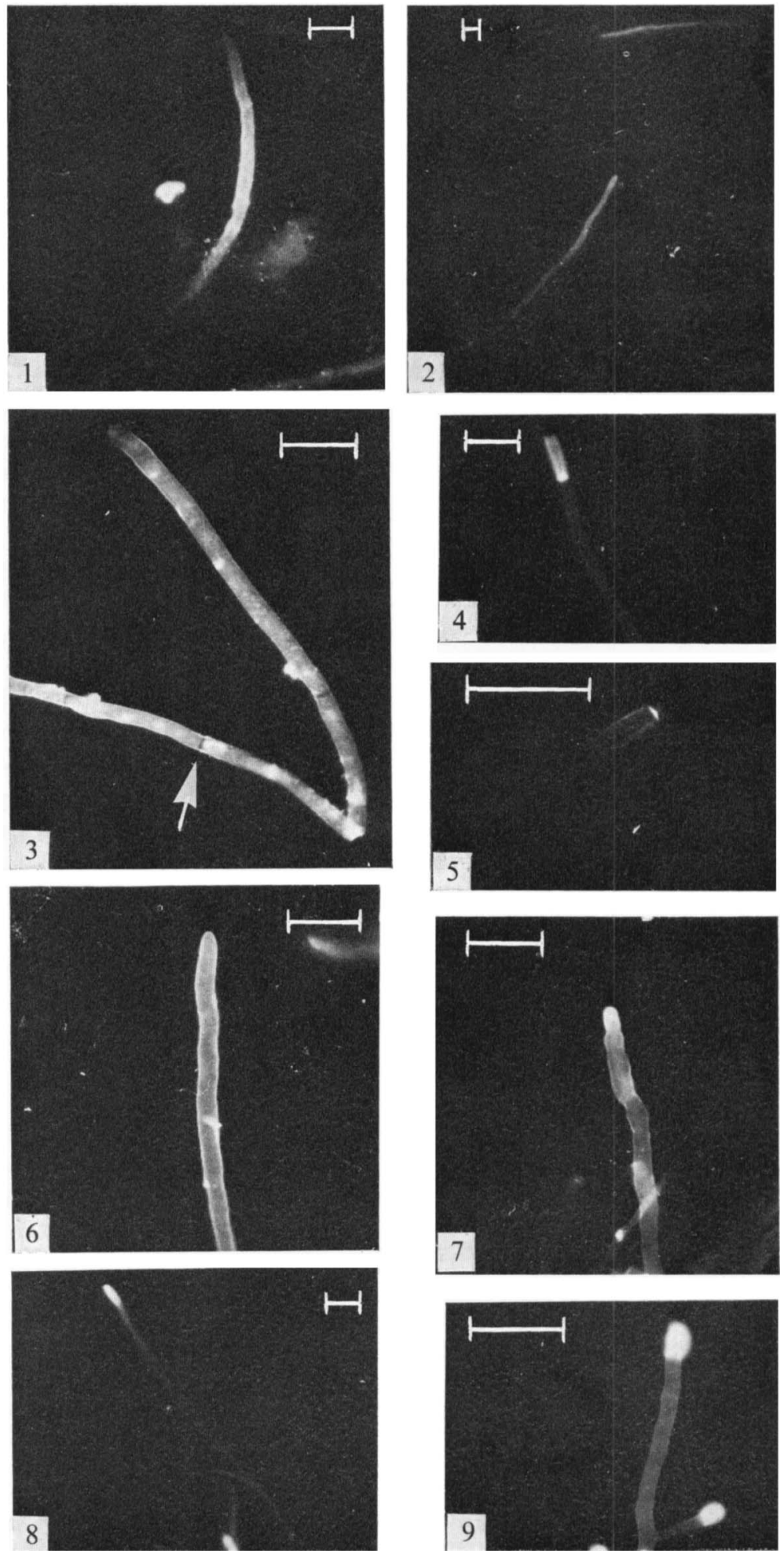
Only when both homologous rabbit antisera to wall components and fluorescein-conjugated sheep antiserum to rabbit globulins were present was fluorescence in the spectral region (green) characteristic of fluorescein observed (Table 4).

The results of immunofluorescent staining procedures with absorbed antisera to wall fractions are presented in Figs I to 8.

Absorbed antiserum to fraction I. Two major types of distribution of fluorescence were frequently observed. The most distinctive (Fig. I) showed a faintly fluorescent apex, with a brightly fluorescent subapical region behind which the fluorescence decreased to a very low level (at about 30 to $50 \mu \mathrm{m}$ behind the apex). In the second type, apices and subapical regions were equally fluorescent, and fluorescence again faded to a low level behind the subapical region at about 50 to $100 \mu \mathrm{m}$ from the apex (Fig. 2).

Absorbed antiserum to fraction III. The fluorescence increased in intensity with distance from the apex and maximum fluorescence was observed in older hyphal regions (Fig. 3). Sometimes the apical dome, i.e. the first 3 to $4 \mu \mathrm{m}$ of the tip, gave a striking appearance of faint fluorescence, being quite sharply defined from the region of increasing fluorescence at the immediate subapex. It is notable also that the positions of septa were seen as areas of non-fluorescence (Fig. 3, arrowed).

Absorbed antiserum to fraction $I V$. Using this antiserum, appreciable fluorescence was o bserved only at the sites where hyphae had been ruptured, extending a short distance back from the break (Figs 4 and 5). Otherwise a very faint, general fluorescence was observed, which was comparable to levels of autofluorescence in controls.

Antisera to whole walls. Hyphae stained with unabsorbed antisera to walls from 24 and I $20 \mathrm{~h}$ cultures gave similar fluorescence patterns (Fig. 6). Usually hyphae showed an even distribution of fluorescence. Very occasionally, preparations made with unabsorbed antiserum to walls from $24 \mathrm{~h}$ cultures showed brightly fluorescing tips (Fig. 7); but preparations stained with unabsorbed antiserum to walls from $\mathrm{I} 20 \mathrm{~h}$ cultures never showed increased fluorescence in non-apical areas. Absorbed antisera to walls from 24 and $120 \mathrm{~h}$ cultures produced similar types of u.v. fluorescence in which hyphal tips were brightly fluorescent while subapical areas were faintly fluorescent (Fig. 8).

Staining of hyphae with an optical brightener. Hyphae stained with the optical brightener Calcofluor White M2R New showed brightly fluorescent tips (Fig. 9). Intense fluorescence extended back from the tip for about 3 to $6 \mu \mathrm{m}$.

\section{Electron microscopy}

Untreated apices and subapical areas. Shadow casts of hyphae washed and dried without any enzymic or chemical treatment showed a roughened amorphous surface (Fig. Io). It was previously suggested (Hunsley \& Burnett, I970) that the microfibrillar wall com-

Electron micrographs of shadow-cast preparations of hyphae from $24 \mathrm{~h}$ cultures of Neurospora crassa. All bar markers represent $0.5 \mu \mathrm{m}$.

Fig. I0. An untreated hyphal apex. Note the amorphous roughened appearance.

Figs II, I 2 and I3. These show the changes in the surface appearance of a hypha with increasing distance from its apex. In subapical area, the reticulate structure of the wall is readily visible on the surface (Fig. II) while further back it becomes progressively occluded (Fig. I2) until finally the amorphous appearance of mature hyphal regions is seen (Fig. I3).

Fig. 14. A hyphal apex treated with pronase. Note the randomly arranged microfibrils.

Fig. 15. A hyphal apex which has undergone a drastic chemical treatment to remove amorphous wall components. Note the randomly arranged microfibrils. 

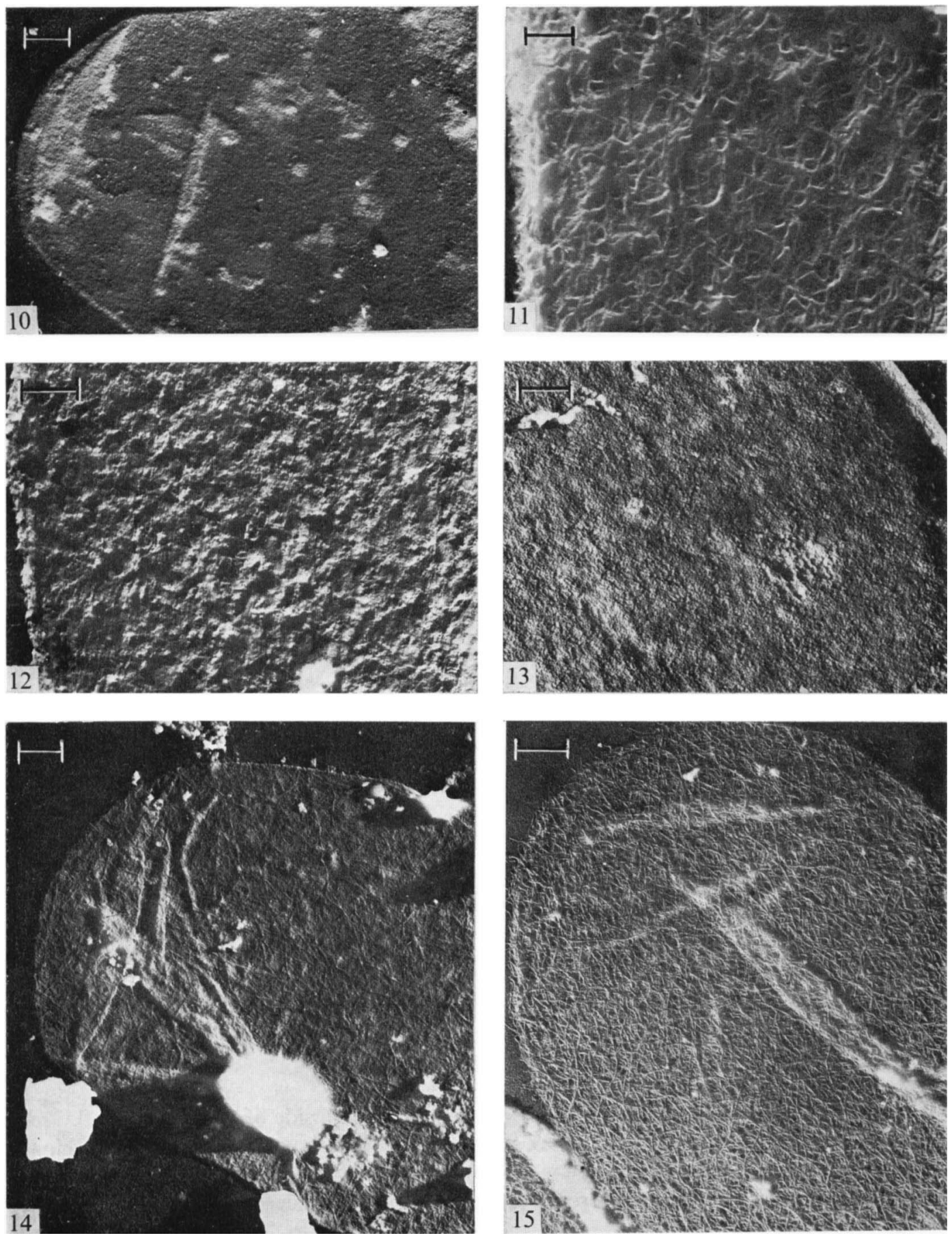


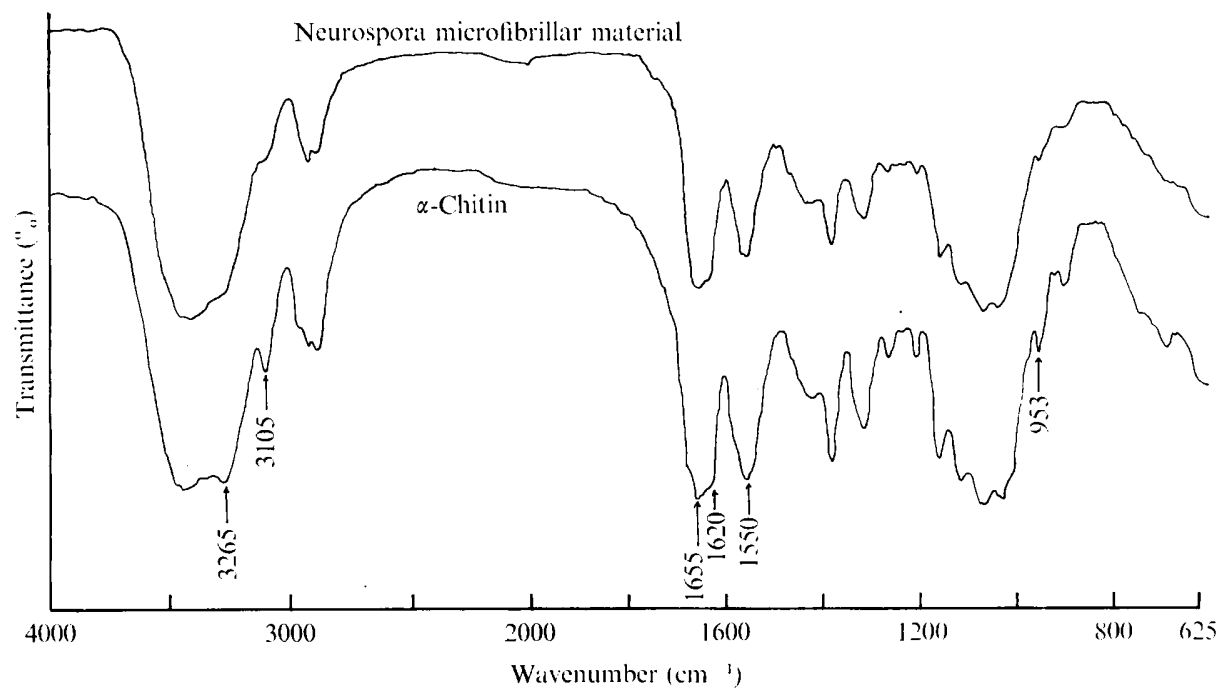

Fig. 16. Infrared absorption spectra of Neurospora microfibrillar material and $\alpha$-chitin.

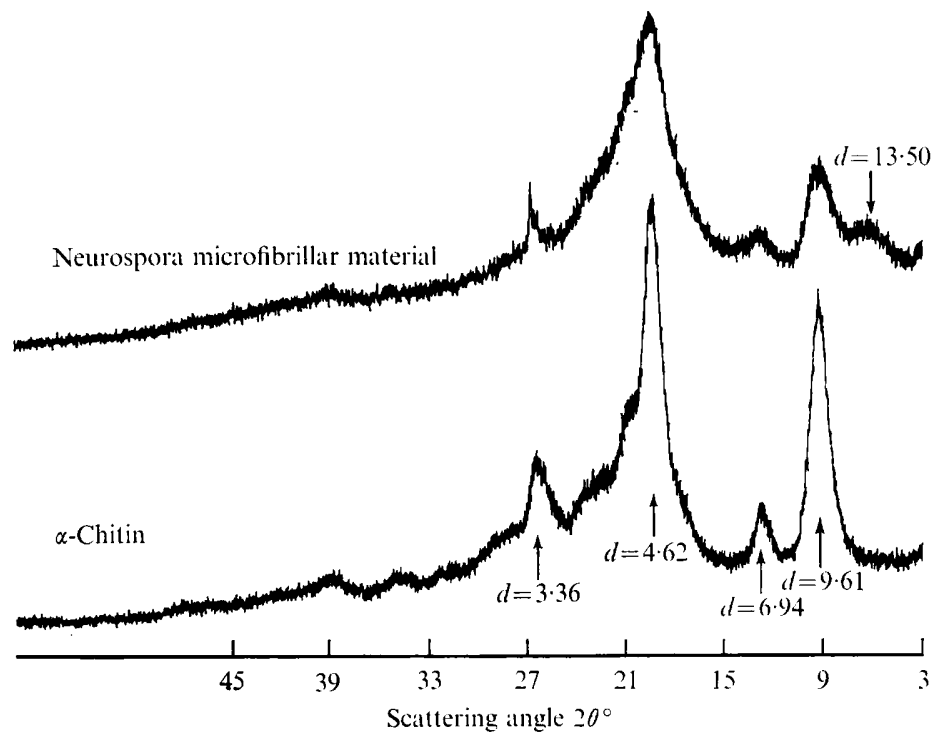

Fig. 17. X-ray powder diffraction diagrams of Neurospora microfibrillar material and $\alpha$-chitin. Lattice spacings $(d)$ are given in $\AA$.

ponents of hyphae from $\mathrm{I} 20 \mathrm{~h}$ cultures were located on the inside of the mature wall. Preparations of untreated apices (Hunsley \& Burnett, 1970) also showed the subapical development of a reticulate structure on the wall surface. With increasing distance from the apex this structure became better developed and eventually was occluded by amorphous material (Figs II, 12 and I3).

Enzymic treatments of hyphal tips. Enzymic treatments were employed to try and determine the nature of the amorphous surface material at hyphal apices using the microfibrils on the inside of the wall as a marker to indicate removal of some or all of the surface material. However, enzymic dissection methods employed on young hyphal material did not give 
very reproducible results. Because of their tendency to burst, the tips could not be subjected to the treatment previously used to inactivate the autolytic enzymes of Phytophthora walls (Hunsley, 1973). Nevertheless treatment of tips with pronase followed by shadow casting often revealed randomly arranged microfibrils (Fig. I4). However, this apparent removal of wall proteins overlying microfibrils should be viewed with caution as it could well have been partly or largely due to autolytic enzymes acting on wall components.

Drastic chemical treatment of apices. Shadow-cast preparations of chemically treated hyphae from $24 \mathrm{~h}$ cultures revealed randomly oriented microfibrils at the hyphal apex (Fig. I5). Measurements of shadow lengths from both enzymic and chemically treated apices indicated that the microfibrillar part of the wall at the apex had a thickness of about $40 \mathrm{~nm}$. The microfibrillar material remaining after the drastic chemical treatment had a similar infrared spectrum to that of a reference standard of purified crustacean $\alpha$-chitin. Peaks in the absorption spectra at $3265,3105,1655,1620,1550$ and $953 \mathrm{~cm}^{-1}$, which are attributable to various bond-stretching phenomena or groupings in chitin (Mitchell \& Scurfield, 1967), were shown by both samples (Fig. I6).

Figure 17 shows X-ray powder diffraction diagrams of Neurospora microfibrillar material and $\alpha$-chitin. The main lattice spacings in the $\alpha$-chitin diagram can also be seen in the diagram given by the Neurospora microfibrillar material: the latter has weaker reflexions, indicating a lower crystallinity, and an additional weak reflexion at $13.50 \AA$.

Apical and non-apical hyphal walls in section. Figure 18 shows a median, or near median, section through the hyphal apex of Neurospora. This was unequivocally identified as a section of a hyphal apex because of the presence of the spitzenkorper and the surrounding large electron-opaque vesicles (Grove \& Bracker, 1970). Figure 19 is an enlargement of the extreme apical area: the plasmalemma is resolvable as a unit membrane, which is another indication of a median section. The wall at the extreme apex is about $50 \mathrm{~nm}$ thick. Figure 20 is a section from just under the apical dome showing that, at this point, the wall does not appreciably increase in thickness (wall thickness here, taken as the mean of a number of measurements from the exterior of the plasmalemma to the outer part of the dense area of the wall, is about $60 \mathrm{~nm}$ ). Figure $2 \mathrm{I}$ is a section from the more distant subapex showing material protruding from the outer surface of the wall. It is thought that this corresponds to the area where the reticulate structure of the wall starts to be visible in shadow-cast preparations (see Hunsley \& Burnett, 1970, Fig. 59). Sections of mature hyphal regions (about $5 \mathrm{~mm}$ from the apex in hyphae from $120 \mathrm{~h}$ cultures; Fig. 22) reveal that the wall has a thickness of about $125 \mathrm{~nm}$ and shows the three-layered structure described previously (Hunsley \& Burnett, 1970). A comparison of measurements of wall thickness in hyphae from apical areas of $24 \mathrm{~h}$ cultures with those of hyphae from non-apical areas of $\mathrm{I} 2 \mathrm{o} \mathrm{h}$ cultures $(n=100)$ was made. The hyphal wall in apical regions is significantly thinner than the wall in mature regions (at the $5 \%$ level). Figure 23 presents these results in the form of histograms.

\section{DISCUSSION}

It has been reported, both as casual observations (Grove, Bracker \& Morré, 1970; Gibson \& Peberdy, 1972) and as the results of more deliberate investigations (Hunsley 1973; Trinci \& Collinge, 1975), that the hyphal wall at fungal apices is considerably thinner than the lateral hyphal wall some distance below the apex. Trinci \& Collinge (1975) showed that in Neurospora crassa there was no gross increase in wall thickness in the region of wall rigidification below the extension zone as compared with wall thickness at apices. However, at distances of around $10 \mathrm{~mm}$ from the apex, the wall had increased in thickness from 

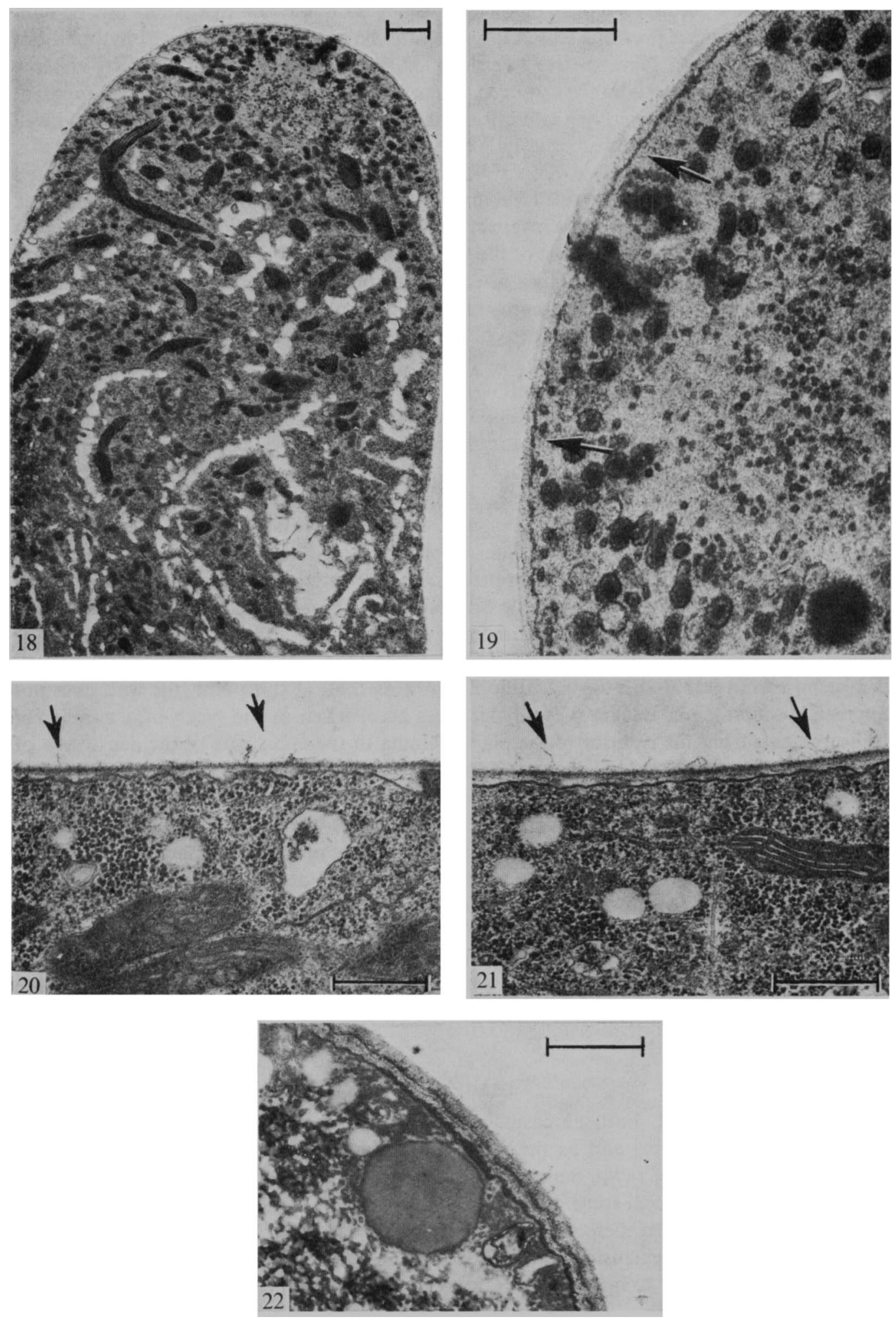
60 to $\mathrm{I} 25 \mathrm{~nm}$. We did not try to determine precisely where the wall starts to thicken, but have shown that around $5 \mathrm{~mm}$ from the apex the wall is approximately twice as thick as at the tip: this agrees with Trinci \& Collinge's (1975) determination.

We consider that the wall at the hyphal apex consists of an inner layer of chitin microfibrils covered by a layer of amorphous material. Immunofluorescence shows that this amorphous region has present on its surface small amounts of wall components corresponding to fraction III (laminarin-like glucan), and also, depending upon the individual hypha observed, either small or large amounts of fraction I (glucan-peptide-galactosamine complex). Hyphae which have small amounts of this complex present may have stopped extending, since in $120 \mathrm{~h}$ cultures the complex (i.e. reticulate structure of the wall) often encroached upon the apex (Hunsley \& Burnett, I970). Immunofluorescence results for hyphal apices that appear to possess only small amounts of the complex, correspond well with ultrastructural observations (see Hunsley \& Burnett, 1970, Fig. 59, which showed the subapical development of the complex). With the immunofluorescence technique, one can demonstrate the presence of small amounts of the complex at the apex which are not resolvable as discrete structures in shadow-cast electron micrographs.

Immunofluorescence observations indicate that the complex is usually most prominent behind the immediate subapical region of hyphae from $24 \mathrm{~h}$ cultures and becomes masked with some other material further down the hyphae. This deduction is confirmed by direct observation in shadow-cast electron micrographs (Figs I I, I 2, I4 and Hunsley \& Burnett, I970, Fig. 59). One component of the occluding material may be fraction III, the laminarinlike glucan, since immunofluorescence preparations using antibodies to this fraction show a progressive increase in fluorescence with distance from the tip to areas below the subapical region.

Immunofluorescence results also indicated a localization of fraction IV (chitin) on the inside of the wall in accordance with previous suggestions (Hunsley \& Burnett, 1970). All these observations are incorporated in diagrammatical form, together with some features from the last quoted work, in Fig. 24.

The fungal wall is a highly complex structure. Thus although Wrathall \& Tatum (1973) concluded that the glycopeptide (i.e. the complex, fraction I) structure of the Neurospora hyphal wall is not demonstrably covalently linked to other major wall components, there

Electron micrographs of hyphae from 24 h cultures of Neurospora crassa.

All bar markers represent $0.5 \mu \mathrm{m}$.

Fig. I 8. Longitudinal section through a hyphal apex showing the extremely thin wall at the apex. Note also the presence of the central spitzenkorper and surrounding electron-opaque vesicles.

Fig. 19. Enlargement of the extreme apical region in Fig. I8. Note the lack of layering in the apical wall. The presence of the spitzenkorper and the unit membrane structure of the plasmalemma (arrowed) indicates that this is a median or near median section. The apical wall is about $50 \mathrm{~nm}$ thick.

Fig. 20. Section showing the immediate subapical region of the hyphal wall. The wall is not appreciably thicker here than at the apex (about $60 \mathrm{~nm}$ ). There are some indications of material protruding from the wall surface (arrowed). This is thought to correspond to the start of the development of the reticulate structure visible in shadow-cast preparations.

Fig. 2I. Section of subapical region of the hyphal wall, further back from apex than Fig. 20, showing that the protruding material is becoming better developed (arrowed).

Fig. 22. Section of a mature region of the hyphal wall. Note the essentially three-layered structure of the wall. The median electron-opaque layer is thought to correspond to the reticulate structure of the wall which has become obscured in surface view by the addition of amorphous material to the wall surface. 

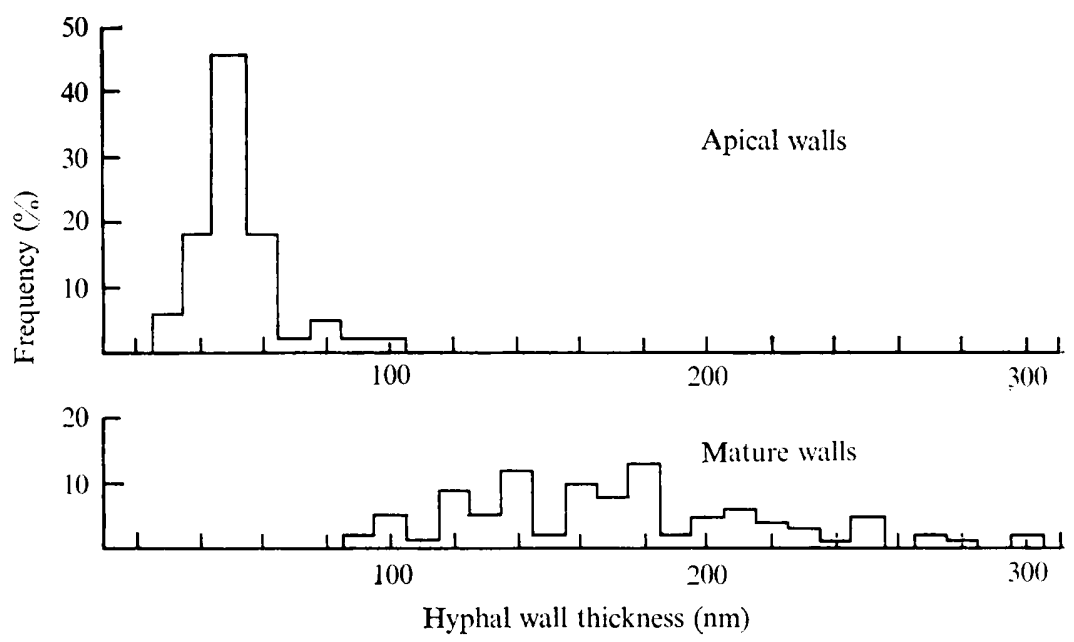

Fig. 23. Histograms showing the distribution of wall thickness in apical and mature regions of Neurospora hyphae, as measured from thin sections.

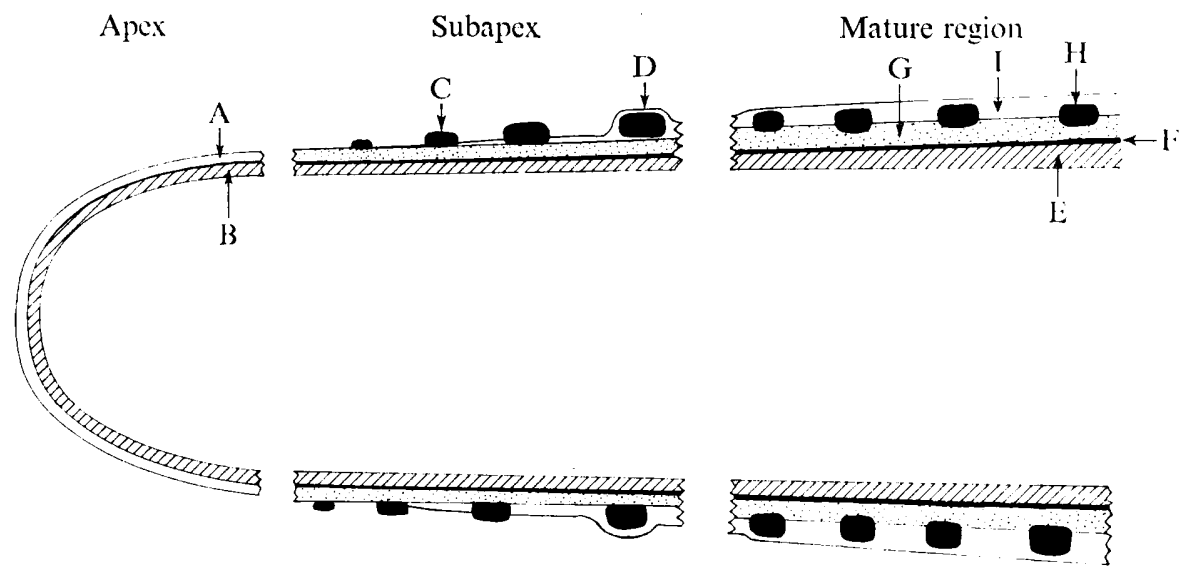

Fig. 24. Diagrammatical representation of the wall structure in apical, subapical and mature regions of Neurospora hyphae, incorporating the results of surface component reactions with the antisera employed in this study. Diagram not to scale.

Apical region. A, Amorphous covering of the apex (possibly removable by pronase). This reacts with: antiserum to fraction I (glucan-peptide-galactosamine complex), weak or strong reaction; antiserum to fraction III (laminarin-like glucan), weak reaction; and also with antibodies to uncharacterized antigens remaining after antisera to 24 and $120 \mathrm{~h}$ culture walls are absorbed with fractions I, III and IV, strong reaction. B, Inner regions of the apical wall containing chitin microfibrils.

Subapical region. C, Reticulate structure of the wall (glucan-peptide-galactosamine complex), visible on the surface. D, Laminarin-like glucan covering the reticulum in the proximal part of the subapical region. The subapical region surface reacts with: antiserum to fraction I, strong reaction; antiserum to fraction III, moderate reaction.

Mature region. E, Inner chitin/protein region of the wall. F, Discrete layer of protein. G, Easily removable protein. H, Reticulate structure of the wall embedded in outer glucan. I, Outer amorphous layer of laminarin-like glucan. The mature region surface reacts with: antiserum to fraction I, very weak reaction; antiserum to fraction III, strong reaction. 
is evidence in other filamentous fungi of a close association of, for instance, chitin and glucan wall components (Stagg \& Feather, 1973). At present, it is not clear what degree of association exists in the Neurospora hyphal wall between components other than the glycopeptide complex.

The wall fractions investigated in the present work represent rather less than $35 \%$ of the dry weight of the Neurospora wild-type wall (Mahadevan \& Tatum, 1965). It is not surprising therefore that both immunodiffusion and immunofluorescence methods, using antisera to whole walls that have been absorbed with fractions I, III and IV, give evidence for the presence of antibodies to as yet uncharacterized wall antigens. One component of these antigens may be wall proteins other than peptides of fraction I, since treatment of apices of hyphae from $24 \mathrm{~h}$ cultures with pronase unmasked wall microfibrils at the tip, indicating that one component of the overlying amorphous material may be protein. However, the reservations about this observation mentioned earlier should be borne in mind.

One aspect of apical wall structure that deserves comment is the distinctive binding properties of the wall surface at the apical dome itself. This is seen in the binding of the optical brightener Calcofluor White M2R New, an observation which has been reported previously (Gull \& Trinci, 1974). These authors suggested that the increased binding ability of the wall at the apex was a result of localized cell-wall lysis, resulting in an increase in receptor sites. Wall lysis has already been implicated as an essential component of apical growth (BartnickiGarcia \& Lipmann, 1972; Bartnicki-Garcia, 1973).

A similar pattern of increased binding at the apical dome wall is seen in the immunofluorescence micrographs of hyphae from $24 \mathrm{~h}$ cultures treated with antiserum to whole walls from $24 \mathrm{~h}$ cultures which has been absorbed to remove antibodies to fractions I, III and IV, i.e. there is increased binding of antibodies to the uncharacterized antigens mentioned above. The reverse situation is seen with antibodies to fraction III. In this case, the apical dome is sharply delineated as an area of low level fluorescence, the intensity of which soon increases behind the dome. These observations, together with the effects of pronase on apices of hyphae from $24 \mathrm{~h}$ cultures reported above, may suggest that the hyphal surface at the apical dome wall is largely occupied by protein components which, in older hyphal regions, form part of the innermost wall area covering the chitin microfibrils. The apical dome wall may thus represent what is substantially the inner region of mature walls, a suggestion that has already been made by Trinci \& Collinge (1975). The present model (Fig. 24) would modify this concept slightly in that sparse amounts of glucan (fraction III) and either sparse or substantial (depending on the individual hypha observed) amounts of fraction $I$ are also present.

It is implicit in this model of wall structure that as a hypha ages, i.e. as one proceeds back from the apex, new wall material is synthesized on the outside of the existing wall remote from cytoplasmic contact. Reissig (1974) has also drawn attention to the possible perisemic function of the fraction I complex in restricting growth to the apex. Both of these latter observations raise interesting problems in the control of synthesis of particular wall components and in the control of hyphal growth generally, which perhaps deserve further investigation.

We are grateful for the assistance and advice of Miss C. Court, Department of Human Anatomy, University of Oxford and Mr K. C. Mabbatt, Mr J. Kent and Mr S. A. Buckingham, all of the Sir William Dunn School of Pathology, University of Oxford. We are also grateful to Dr A. P. J. Trinici for allowing us to see work prior to publication. 


\section{REFERENCES}

Bartnicki-Garcia, S. (1973). Fundamental aspects of hyphal morphogenesis. Symposium of the Society for General Microbiology 23, 245-267.

Bartnicki-Garcia, S. \& LipmanN, E. (1972). The bursting tendency of hyphal tips of fungi: presumptive evidence for a delicate balance between wall synthesis and wall lysis in apical growth. Journal of General Microbiology 73, 487-500.

Gibson, R. K. \& Peberdy, J. F. (1972). Fine structure of protoplasts of Aspergillus nidulans. Journal of General Microbiology 72, 529-538.

Goldman, M. (I968). Fluorescent Antibody Methods. New York and London: Academic.

Grove, S. N. \& Bracker, C. E. (1970). Protoplasmic organisation of hyphal tips amongst fungi: vesicles and spitzenkörper. Journal of Bacteriology ro4, 989-1009.

Grove, S. N., Bracker, C. E. \& Morré, D. J. (1970). An ultrastructural basis for hyphal tip growth in Pythium ultimum. American Journal of Botany 57, 245-266.

Gull, K. \& Trinci, A. P. J. (1974). Detection of areas of wall differentiation in fungi using fluorescent staining. Archives of Microbiology 96, 53-57.

Holland, A. A. \& CHOo, Y. SEN (1970). Immunoelectrophoretic characteristics of Ophiobolus graminis. Sacc. as an aid in classification and determination. Antonie van Leeuwenhoek 36, 54 I-548.

HunsLey, D. (1973). Apical wall structure in hyphae of Phytophthora parasitica. New Phytologist 72, 985990.

Hunsley, D. \& Burnett, J. H. (I968). Dimensions of microfibrillar elements in fungal walls. Nature, London 218, 462-463.

HunsleY, D. \& Burnet, J. H. (1970). The ultrastructural architecture of the walls of some hyphal fungi. Journal of General Microbiology 62, 203-2 18.

Mahadeven, P. R. \& TATUM, E L. (1965). Relationship of the major constituents of the Neurospora crassa cell wall to wild-type and colonial morphology. Journal of Bacteriology 90, 1073-108I.

Mitchell, A. J. \& Scurfield, G. (1967). Composition of extracted fungal cell walls as indicated by infrared spectroscopy. Archives of Biochemistry and Biophysics 120, 628-637.

OAKLEY, C. L. (197I). Antigen-antibody reactions in microbiology. In Methods in Microbiology, vol. 5A, pp. 173-21 8. Edited by J. R. Norris and D. W. Ribbons. London and New York: Academic.

Ouchterlony, O. (1964). Gel-diffusion techniques. In Immunological Methods, Symposium of the Council for International Organizations of Medical Sciences, pp. 55-91. Oxford: Blackwell.

Reissig, J. L. (1974). Decoding of regulatory signals at the microbial surface. Current Topics in Microbiology and Immunology 67, 43-96.

ReYnolds, E. S. (1963). The use of lead citrate at high $\mathrm{pH}$ as an electron-opaque stain in electron microscopy. Journal of Cell Biology 17, 208-2 I 2.

SARGENT, J. R. (I97I). Zone electrophoresis of the separation of microbial cell components. In Methods in Microbiology, vol. 5B, pp. 455-51 2. Edited by J. R. Norris and D. W. Ribbons. London and New York: Academic.

Skujins, J. J., Potgieter, H. J. \& Alexander, M. (I965). Dissolution of fungal cell walls by a Streptomycete chitinase and $\beta-(\mathrm{I} \rightarrow 3)$-glucanase. Archives of Biochemistry and Biophysics IIr, 358-364.

StAGG, C. M. \& FeatheR, M.S. (I973). The characterization of a chitin-associated D-glucan from the cell walls of Aspergillus niger. Biochimica et biophysica acta 320, 64-72.

Trinci, A. P. J. \& Collinge, A. J. (I975). Hyphal wall growth in Neurospora crassa and Geotrichum candidum. Journal of General Microbiology 91, 355-36I.

Weller, J. H. \& Coons, A. H. (I954). Fluorescent antibody studies with agents of Varicella and Herpes zoster propagated in vitro. Proceedings of the Society for Experimental Biology and Medicine 86, 789794.

Wrathall, C. R. \& TAtum, E. L. (1973). The peptides of the hyphal wall of Neurospora crassa. Journal of General Microbiology 78, 139-1 53. 